\title{
The new approach to organocatalysts. Synthesis of a library of $N$-lipidated oligopeptides immobilized on cellulose and screening of their catalytic activity
}

\author{
Justyna Fraczyk, Beata Kolesinska and Zbigniew J. Kaminski* \\ Institute of Organic Chemistry, Technical University of Lodz, Zeromskiego 116, \\ 90-924 Lodz, Poland \\ E-mail: zbigniew.kaminski@p.lodz.pl
}

Dedicated to Professor Pawel Kafarski on the occasion of his 63rd birthday

\begin{abstract}
A library of $N$-lipidated tripeptides was prepared from amino acids characteristic of the active sites of hydrolytic enzymes: Ser, His, and Glu immobilized in the highly regular pattern on the cellulose surface according to TASP concept. It was found that such structures can accelerate the rate of hydrolysis of p-nitrophenyl esters of $N$-protected dipeptides.
\end{abstract}

Keywords: Organocatalysis, supramolecular, self-organization, artificial enzyme, chemzyme, catalysis

\section{Introduction}

Structures formed by $N$-lipidated oligopeptides immobilized in a regular pattern on a cellulose surface via triazine linker are able to recognize the shape and properties of ligands, and then selectively bind guest molecules matching the requirements of the binding pocket. ${ }^{1}$ Due to the conformational flexibility of both interacting partners, the relative direction of the functional groups of a ligand as well as that of the binding pockets could be readjusted to the most energetically favored orientation of both counterparts. Our previous studies documented that the process of binding guest molecules is reversible and competitive. ${ }^{2}$ Inspired with this observation, we assumed that under favorable circumstances the host structure could operate as a catalyst if suitable functional groups ${ }^{3}$ were incorporated into the molecular fragments forming the binding pocket. In order to verify this hypothesis, we prepared a library of 36 supramolecular tripeptide structures with permutations of His, Glu, and Ser residues to study their catalytic activity. 


\section{Results and Discussion}

According to the presented concept, catalytically active structures are expected to be formed by self-organization of $N$-lipidated oligopeptides immobilized on the cellulose surface. The synthesis commenced with modification of cellulose (1) surface by treatment with 2,4-dichloro1,3,5-triazine (2) followed by reaction with $m$-phenylenediamine (3) according to the synthetic procedure described previously [1]. The sub-libraries of tripeptides were prepared with the diversomer strategy using Fmoc-Glu(tBu)-OH (4), Fmoc-Ser(tBu)-OH (5) and Fmoc-His(Trt)$\mathrm{OH}(6)$. Fmoc protection for the $\alpha$-amino group was removed with $20 \%$ piperidine in DMF. In the synthesis of the peptide fragment, DMT/NMM/BF4- (7) was used ${ }^{4}$ as a coupling reagent. For the final acylation of immobilized tripeptides with carboxylic acid, DMT/NMM/TosO- $(8)$ was found more suitable ${ }^{5}$ as a coupling reagent. Acid-labile side-chain protecting groups were removed by treatment with $50 \%$ trifluoroacetic acid in dichloromethane. The final products of the synthesis was a library of 36 structures formed by permutations of Ser, Glu, His triade acylated with 6 long chain carboxylic acids 9-14.

In the preliminary experiments, $p$-nitrophenyl ester of Z-L-Leu-L-Leu-OH was applied as a substrate to determine the catalytic activity of $N$-lipidated tripeptides immobilized on cellulose. It is already known ${ }^{6}$ that hydrolysis of this substrate proceeds effectively at $\mathrm{pH} \geq 9.5$ and a temperature exceeding $30^{\circ} \mathrm{C}$.

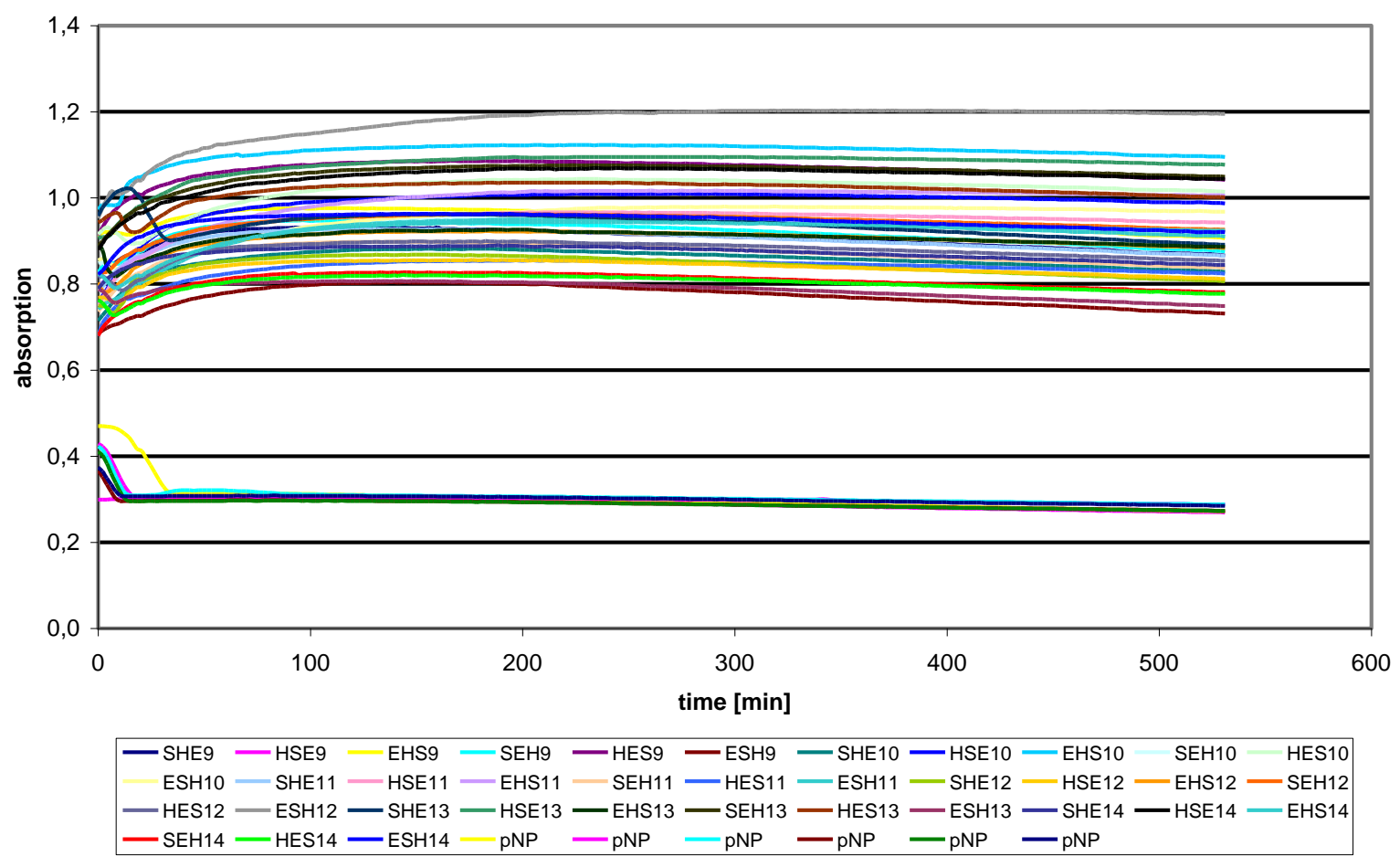

Figure 1. The rate of hydrolysis of Z-L-Leu-L-Leu-ONp (15) at $20{ }^{\circ} \mathrm{C}$ in aqueous methanol at $\mathrm{pH} 7$ in the presence of a library of $N$-lipidated tripeptides immobilized on cellulose. 
Spectrophotometric determination of the amount of $p$-nitrophenol liberated confirmed that ZL-Leu-L-Leu-ONp (15) is stable in buffered $(\mathrm{pH}=7)$ aqueous methanol at $20{ }^{\circ} \mathrm{C}$; however, all 36 structures designed as permutations of the catalytic triad catalyzed the hydrolysis of $\mathbf{1 5}$ under conditions described above (see Figure 1).

The progress of hydrolysis was so fast that under the conditions of the experiment it was difficult to identify the most catalytically active structure. The extinction at $405 \mathrm{~nm}$ increased from the initial value of 0.300 for the substrate to more than 0.800 before the first cycle of measurements was completed. Therefore, at the next stage of the study on the catalytic activity of the library of $\mathrm{N}$-lipidated peptides a less reactive Z-Ala-Aib-ONp (16) was used as substrate. As previously, the catalytic activity was measured by spectrophotometric determination of $p$ nitrophenol formed from 16 in aqueous methanol buffered at $\mathrm{pH} 7$ in the presence of appropriate $N$-lipidated peptides (see Figure 2). It has been found that $p$-nitrophenyl ester of the dipeptide 16 with an $\alpha, \alpha$-disubstituted Aib residue in the $C$-terminal position hydrolyzed substantially less readily, and the rate of reaction was diversified enough to identify the structures with the highest catalytic activity.

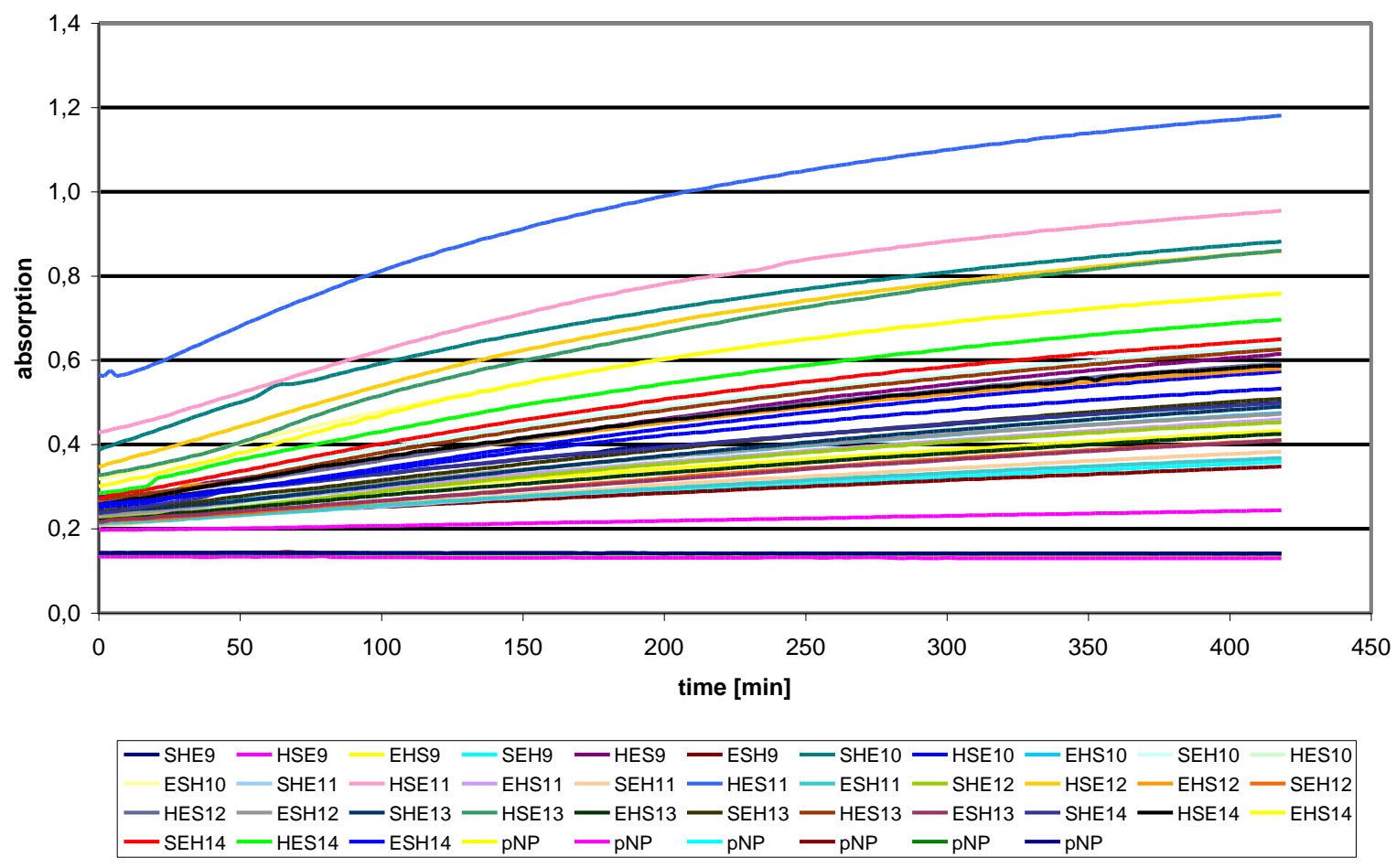

Figure 2. The rate of hydrolysis of Z-L-Ala-Aib-ONp (16) at $20{ }^{\circ} \mathrm{C}$ in aqueous methanol at $\mathrm{pH} 7$ in the presence of a library of $\mathrm{N}$-lipidated tripeptides immobilized on cellulose.

For the branched substrate $\mathbf{1 6}$ only five structures were distinguished as the most active from the 36 element library of $\mathrm{N}$-lipidated tripeptides. These were: i) undec-10-enoyl-HES-NH- ${ }_{6} \mathrm{H}_{4}-$ NH-1,3,5-triazinyl-cellulose (11,H,E,S), ii) undec-10-enoyl-HSE-NH-C $6 \mathrm{H}_{4}-\mathrm{NH}-1,3,5$-triazinyl- 
cellulose (11,H,S,E), iii) (Z)-docos-13-enoyl-SHE-NH-C ${ }_{6} \mathrm{H}_{4}-\mathrm{NH}$-1,3,5-triazinyl-cellulose $(\mathbf{1 3}, \mathbf{H}, \mathbf{S}, \mathbf{E})$, iv) decanoic-ESH-NH-C 6 H4-NH-1,3,5-triazinyl-cellulose (12,H,S,E), and v (9Z,12R)-12-hydroxyoctadec-9-enoyl-S,H,E-NH-C ${ }_{6} \mathrm{H}_{4}-\mathrm{NH}-1,3,5$-triazinyl-cellulose (10,S,H,E). The lowest activity was observed for $(E)$-octadec-9-enoyl-HSE-NH-C $6 \mathrm{H}_{4}-\mathrm{NH}-1,3,5$-triazinylcellulose (9,H,S,E), (E)-octadec-9-enoyl-SEH-NH-C ${ }_{6} \mathrm{H}_{4}-\mathrm{NH}-1,3,5$-triazinyl-cellulose (9,S,E,H), (E)-octadec-9-enoyl-ESH-NH-C $6 \mathrm{H}_{4}-\mathrm{NH}$-1,3,5-triazinyl-cellulose $\quad(\mathbf{9 , E , S , H}), \quad$ undec-10-enoylSHE-NH-C ${ }_{6} \mathrm{H}_{4}-\mathrm{NH}-1,3,5$-triazinyl-cellulose (11,S,H.E), undec-10-enoyl-ESH-NH-C ${ }_{6} \mathrm{H}_{4}-\mathrm{NH}-$ 1,3,5-triazinyl-cellulose (11,E,S,H), undec-10-enoyl-SEH-NH-C $6 \mathrm{H}_{4}-\mathrm{NH}-1,3,5$-triazinylcellulose (11,S,E,H), decanoic-SEH-NH-C ${ }_{6} \mathrm{H}_{4}-\mathrm{NH}-1,3,5$-triazinyl-cellulose (12,S,E,H), (Z)docos-13-enoyl-ESH-NH-C $6 \mathrm{H}_{4}-\mathrm{NH}-1,3,5$-triazinyl-cellulose $(\mathbf{1 3}, \mathbf{E}, \mathbf{S}, \mathbf{H})$ and decanoic-EHS-NH$\mathrm{C}_{6} \mathrm{H}_{4}-\mathrm{NH}-1,3,5$-triazinyl-cellulose $(\mathbf{1 2}, \mathbf{E}, \mathbf{H}, \mathbf{S})$. In this case hydrolysis proceeded slowly, yet still noticeably faster compared to blank experiments.

To disclose the structural fragments most important for hydrolytic activity, the progress of reaction reached after $418 \mathrm{~min}$. at the final experiment of kinetic cycle measurements was compared for each carboxylic acid (Figure 3) and each amino acid sequence (Figure 4).

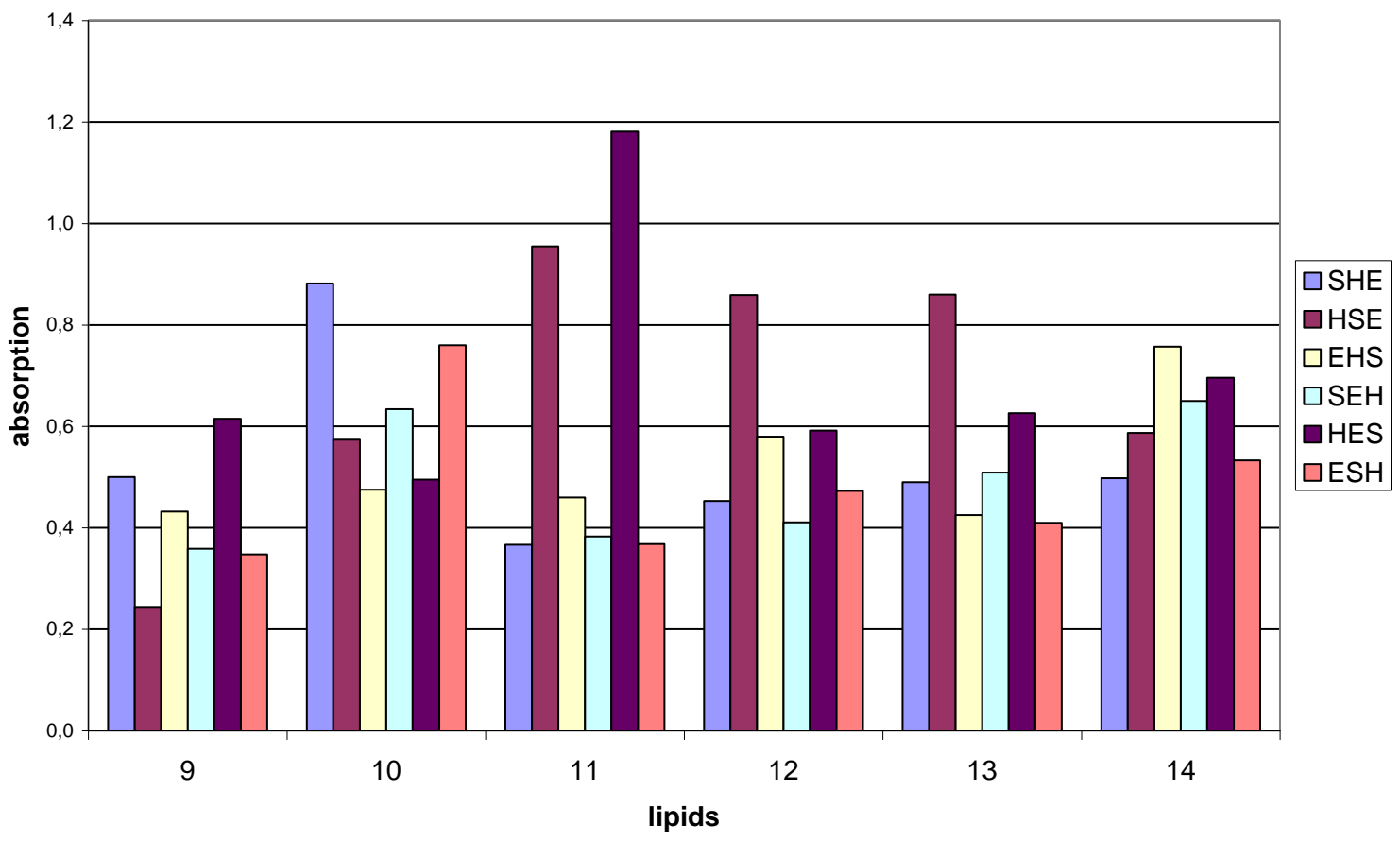

Figure 3. Progress of hydrolysis of Z-Ala-Aib-ONp (16) reached at final kinetic cycle measurement after 418 min. related to carboxylic acid used for $\mathrm{N}$-acylation of tripeptides.

It has been observed that both fragments control the reaction. Relatively poor reactivity was found for all peptides $N$-acylated with long chain, unsaturated $(Z$ )-octadec-9-enoic acid 9 (Figure 3 , set 9). The most uniform, yet still poor, reactivity has been shown by tripeptides $N$-acylated with long chain octadecanoic acid (14) (Figure 3, set 14). In both these cases catalytic activity 
was less depended on the sequence of peptidic fragment, but probably controlled by diffusion of substrate or products through the lipidic layer.

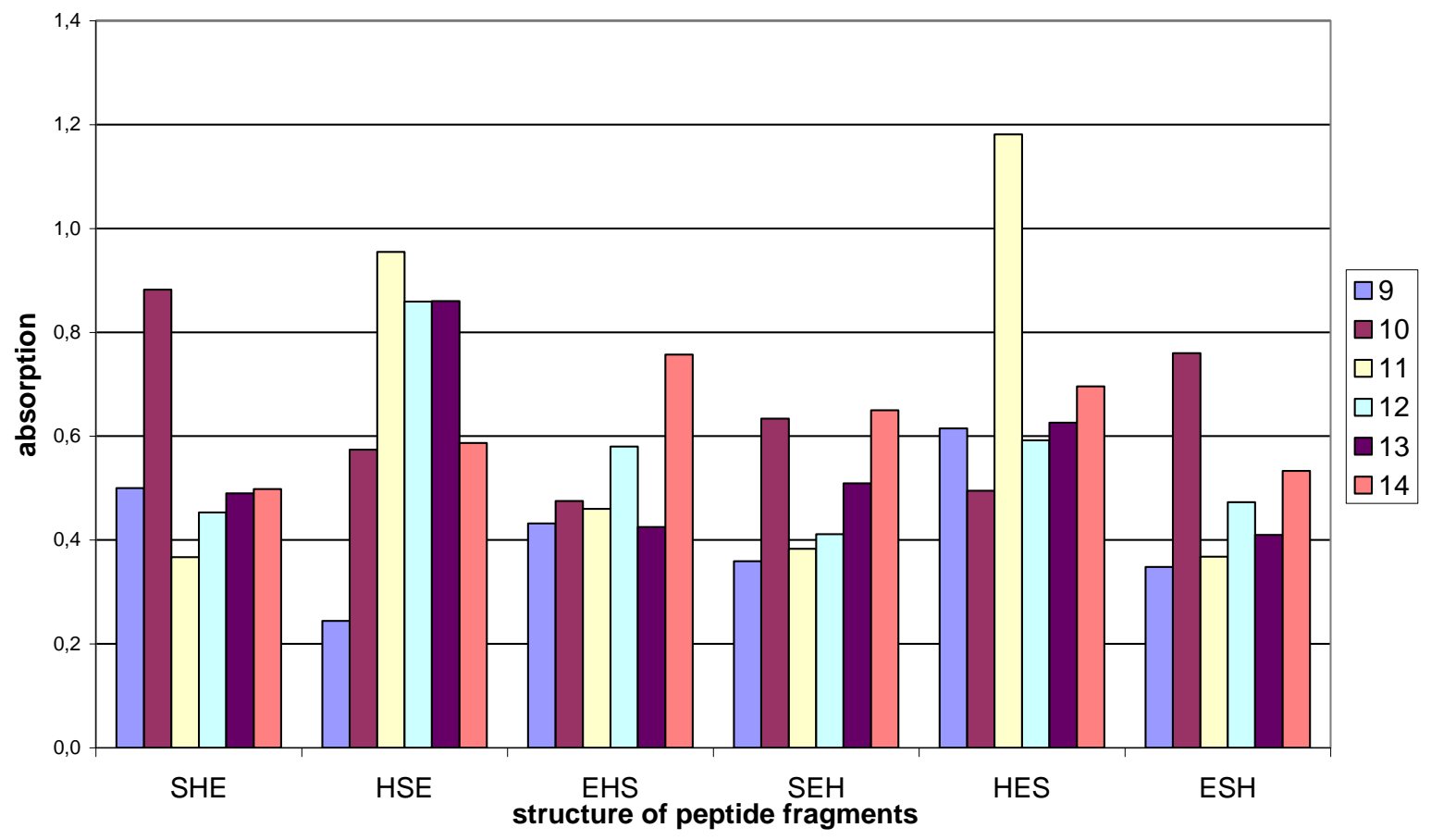

Figure 4. Progress of hydrolysis of Z-Ala-Aib-ONp (16) reached at final kinetic cycle measurement after 418 min. related to amino acid sequence of tripeptide fragment.

Participation of peptide fragment in determining catalytic activity was depicted on Figure 4. The most diversified activity was obtained for structures prepared from relatively short chain undec-10-enoic acid (11) (Figure 4, set 11). Structure of peptide fragment was a factor dominating overall activity and undec-10-enoyl-HES-NH-C ${ }_{6} \mathrm{H}_{4}-\mathrm{NH}-1,3,5$-triazinyl-cellulose $(\mathbf{1 1}, \mathbf{H}, \mathbf{E}, \mathbf{S})$, and undec-10-enoyl-HSE-NH-C $6 \mathrm{H}_{4}-\mathrm{NH}-1,3,5$-triazinyl-cellulose (11,H,S,E) were the catalysts selected from library as most efficient. The next in the rank were $(\mathbf{1 2}, \mathbf{H}, \mathbf{S}, \mathbf{E})$, $(\mathbf{1 3}, \mathbf{H}, \mathbf{S}, \mathbf{E})$, and $(\mathbf{1 0}, \mathbf{S}, \mathbf{H}, \mathbf{E})$. In the four of them histidine occupied $N$-terminal position and in the one case, this residue was located in penultimate position. This strongly suggests the privileged peptide primary structure with histidine residue most exposed inside the binding pocket. For the most active catalysts the abundant in the second position was serine and in the third position glutamic acid residue.

The feature of the less reactive triad sequences was the presence of $(Z)$-octadec-9-enoic acid (9) and undec-10-enoic acid (11). The less reactive peptide sequences were SHE and ESH, but in both cases acylation with $(9 Z, 12 R)$-12-hydroxyoctadec-9-enoic acid (10) substantially increased their catalytic effectiveness.

All these results are consistent with our earlier observation indicating that for the efficient binding of ligands all the elements of the structure of $N$-lipidated peptides are necessary, and the 
most important factor determining binding and recognition of the ligand, is the structure of peptide fragment.

In order to check if the presence of all fragments of the designed structures were obligatory for their catalytic activity, tests for hydrolysis of Z-Ala-Aib-ONp (16) were conducted in the presence of: non-modified 1; cellulose modified with 2,4-dichloro-6-methoxy-1,3,5-triazine (DCMT) then with $m$-phenylenediamine (17); cellulose $O$-acylated with Fmoc-Ala-OH (18); cellulose $O$-acylated with hexadecanoic acid (19); cellulose $O$-acylated with $(E)$-octadec-9-enoic acid (20); cellulose $O$-acylated with nonanoic acid (21); cellulose $O$-acylated with decanoic acid (22); $17 \mathrm{~N}$-acylated with hexadecanoic acid (23); $17 \mathrm{~N}$-acylated with Fmoc-Ala-OH (24); $17 \mathrm{~N}$ acylated with Fmoc-Phe-OH (25); $17 \mathrm{~N}$-acylated with Fmoc-Pro-Ala-OH (26); $17 \mathrm{~N}$-acylated with Boc-Gly-OH (27); $17 \mathrm{~N}$-acylated with $N^{\prime}$-decanoyl-Phe-OH (28); $17 \mathrm{~N}$-acylated with $N^{\prime}$ hexadecanoyl-Phe-OH (29); $17 \mathrm{~N}$-acylated with $N^{\prime}$-decanoyl-Ala-OH (30); $17 \mathrm{~N}$-acylated with $N$ '-decanoyl-Ala-Ala-OH (31) and $17 \mathrm{~N}$-acylated with $N^{\prime}$-decanoyl-L-Ala-Phe-OH (32). The results of these experiments are presented on Figure 5.

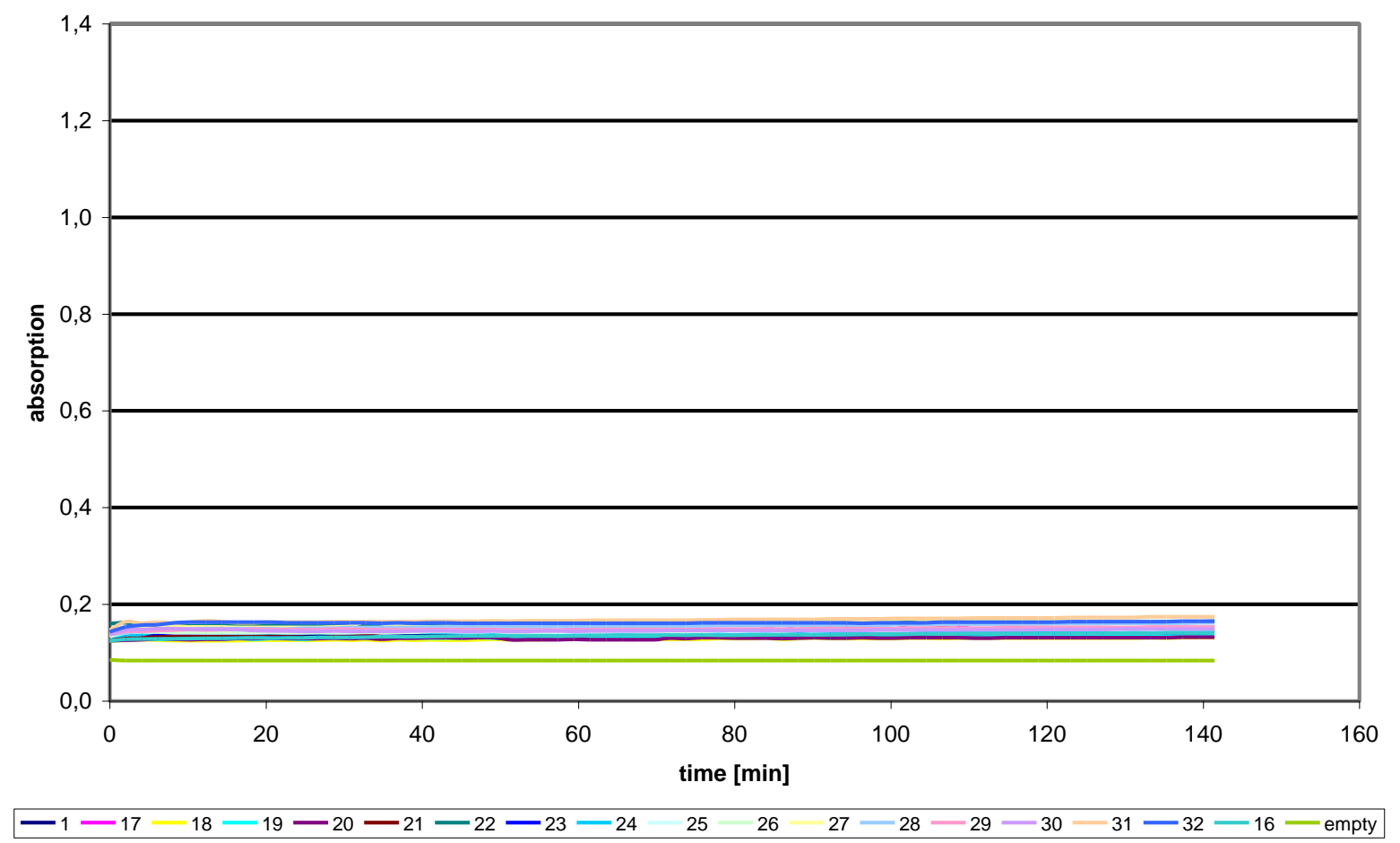

Figure 5. Hydrolysis of Z-Ala-Aib-ONp (16) in the presence of non-modified cellulose (1); cellulose modified with 2,4-dichloro-6-methoxy-1,3,5-triazine (DCMT) then with mphenylenediamine (17); cellulose $O$-acylated with Fmoc-Ala-OH (18); cellulose $O$-acylated with hexadecanoic acid (19); cellulose $O$-acylated with $(E)$-octadec-9-enoic acid (20); cellulose $O$ acylated with nonanoic acid (21); cellulose $O$-acylated with decanoic acid (22); $17 \mathrm{~N}$-acylated with hexadecanoic acid (23); $17 \mathrm{~N}$-acylated with Fmoc-Ala-OH (24); $17 \mathrm{~N}$-acylated with FmocPhe-OH (25). $17 \mathrm{~N}$-acylated with Fmoc-Pro-Ala-OH (26); $17 \mathrm{~N}$-acylated with Boc-Gly-OH (27); $17 \mathrm{~N}$-acylated with $N^{\prime}$-decanoyl-Phe-OH (28); $17 \mathrm{~N}$-acylated with $N^{\prime}$-hexadecanoyl-Phe-OH 
(29); $17 N$-acylated with $N^{\prime}$-decanoyl-Ala-OH (30); $17 N$-acylated with $N^{\prime}$-decanoyl-Ala-Ala$\mathrm{OH}$ (31) and $17 N$-acylated with $N$ '-decanoyl-Ala-Phe-OH (32).

All experiments confirmed that non-modified cellulose (1), incomplete structures 17-22 as well as structures 23-32 without amino acid residues characteristic of the catalytic triad did not promote the hydrolysis Z-Ala-Aib-ONp (16).

\section{Conclusions}

The preliminary data presented above unequivocally confirm that the new type of catalyst prepared by modification of cellulose surface with $N$-lipidated peptides promotes the hydrolysis of ester bonds under very mild conditions. In the case of the library formed by permutations amino acid residues of catalytic triad the most efficient catalysts were structures with the sequence His-Ser-Glu immobilized on cellulose via $m$-phenylenediamine and a 1,3,5-triazine scaffold one can thus hypothesize that the process proceeds inside the "binding pocket" and involves the side chain functionality of the peptide fragment. This is in agreement with our previous SAR studies, strongly suggesting that the process of ligand recognition depends mainly on the structure of amino acid residues. ${ }^{7}$ However, the observations collected so far there are not sufficient for mechanistic considerations of catalytic process. Nevertheless, this finding would open an entirely new prospect for designing organocatalysts, ${ }^{8}$ especially if other catalytic structures could be mimicked with a degree of efficiency comparable to that observed in the case of hydrolysis.

\section{Experimental Section}

Immobilization of 2,4-dichloro-6-methoxy-1,3,5-triazine (DCMT). Forty-six sheets [3 x 6 $\mathrm{cm}$ ] of Whatman-7 filter paper were immersed in $1 \mathrm{M} \mathrm{NaOH}(100 \mathrm{ml})$ and gently shaken for 15 min. An excess of the solution was removed, then the wet sheets of paper were soaked in a suspension of finely ground sodium bicarbonate in 1M solution of 2,4-dichloro-6-methoksy1,3,5-triazine $(18.50 \mathrm{~g})$ in THF $(100 \mathrm{ml})$ and gently shaken for 45 minutes at room temperature. Then cellulose sheets were washed with $2 \mathrm{x}$ THF $(200 \mathrm{ml})$ for 10 minutes, $2 \mathrm{x}$ acetone $(200 \mathrm{ml})$, $2 \mathrm{x}$ acetone: $\mathrm{H}_{2} \mathrm{O} 1: 1(200 \mathrm{ml}), 2 \mathrm{x}$ acetone $(200 \mathrm{ml})$ and $1 \mathrm{x}$ DCM $(200 \mathrm{ml})$, left to remove the remaining solvent and dried in a vacuum desiccator over $\mathrm{P}_{2} \mathrm{O}_{5}$ and $\mathrm{KOH}$ to constant mass.

Elemental analysis: \%N $3.64 \% \mathrm{Cl} 2.66$

Loading of the cellulose plate with triazine was calculated from elemental analysis data. According to nitrogen content $2.60 \mathrm{mmol}(\mathrm{N}) / 1 \mathrm{~g}$; loading calculated was equivalent to ${ }^{\mathrm{N}} \mathrm{Lw}=$ $0.87 \mathrm{mmol}$ (triazine) $/ 1 \mathrm{~g}$. Surface loading calculated according to nitrogen content $31.9 \cdot 10^{-6} \mathrm{~mol}$ (N) $/ \mathrm{cm}^{2}$; which was equivalent to ${ }^{\mathrm{N}} \mathrm{Ls}=10.6 \cdot 10^{-6} \mathrm{~mol}$ (triazine) $/ \mathrm{cm}^{2}$. According to chlorine 
content calculated loading was ${ }^{\mathrm{Cl}} \mathrm{Lw}=0.75 \mathrm{mmol}(\mathrm{Cl}) / 1 \mathrm{~g}$; which was equivalent to ${ }^{\mathrm{Cl}} \mathrm{Ls}=$ $9.2 \cdot 10^{-6} \mathrm{~mol}(\mathrm{Cl}) / \mathrm{cm}^{2}$.

\section{Immobilization of $\boldsymbol{m}$-phenylenediamine. Synthesis of (17)}

Forty-four sheets of paper functionalized by treatment with 2,4-dichloro-6-methoxy-1,3,5triazine (DCMT) were immersed in 1M solution of $m$-phenylenediamine $(14 \mathrm{~g})$ in THF (100 ml) and gently shaken for $24 \mathrm{~h}$ at room temperature, then removed from $m$-phenylenediamine solution, blotted with dry filter paper and washed successively with THF ( 2 x $75 \mathrm{ml})$, DMF ( 2 x $75 \mathrm{ml})$, again THF ( $2 \times 75 \mathrm{ml})$ and then dried in a vacuum desiccator.

Loading of first amino acid. Chemset $17\{\mathbf{S}, \mathbf{E}, \mathbf{H}\}$. Every thirteen sheets $[3 \times 6 \mathrm{~cm}$ ] of 17 for each chemset $\{\mathbf{S}\},\{\mathbf{E}\}$ and $\{\mathbf{H}\}$, were labeled with graphite pencil as S, E, H. The Fmocprotected amino acid (12.5 mmol), $N$-methyl-N-(4,6-dimethoxy-1,3,5 triazin-2-yl) morpholinium tetrafluoroborate (DMT/NMM/BF4'), (4,11 g, $12.5 \mathrm{mmol})$ and HOBt $(1.69 \mathrm{~g}, 12.5 \mathrm{mmol})$ were dissolved in DMF $(35 \mathrm{ml})$ and then NMM $(2,75 \mathrm{ml}, 25 \mathrm{mmol})$ was added. For each Fmocprotected amino acid 13 functionalized cellulose sheets were immersed in the mixture and gently shaken for $24 \mathrm{~h}$. An excess of acylating reagent was removed, then sheets were successively washed by gentle shaking in DMF (3 x $50 \mathrm{ml})$ and DCM (3 x $25 \mathrm{ml})$, then dried in vacuum desiccator. This procedure was used for preparation of chemset $\mathbf{1 7}\{\mathbf{S}\}$ using Fmoc-Ser(tBu)-OH (4.8 g, $12.5 \mathrm{mmol})$, chemset $\mathbf{1 7}\{\mathbf{E}\}$ using Fmoc-Glu(tBu)-OH (5.38 g, $12.5 \mathrm{mmol})$ and chemset $\mathbf{1 7}\{\mathbf{H}\}$ using Fmoc-His(Trt)-OH (7.75 g, $12.5 \mathrm{mmol})$.

Removal of Fmoc-protecting group. Each chemset $17\{\mathbf{S}\}, \mathbf{1 7}\{\mathbf{E}\}$ and $17\{\mathbf{H}\}$ was immersed separately in $25 \%$ solution of piperidine in DMF $(100 \mathrm{ml})$ and gently shaken for 20 minutes, then washed with DMF (3 x $75 \mathrm{ml})$, DCM $(1 \times 75 \mathrm{ml})$ and immediately used in the next synthetic stage.

Incorporation of the second amino acid. The second amino acid was incorporated as described above affording dipeptide chemset with following primary structures of peptide fragment: E,S; $\mathbf{E , H} ; \mathbf{H , S} ; \mathbf{H , E}$; S,E; and S,H immobilized on 17.

Removal of Fmoc-protecting group. Fmoc-protecting groups were removed with 25\% piperidine as described above.

Incorporation of the third amino acid. The third amino acid were incorporated as described above affording tripeptides: E,S,H; E,H,S; H,S,E; H,E,S; S,E,H and S,H,E immobilized on 17. Fmoc-protecting groups were removed with $25 \%$ piperidine as described above.

Incorporation of lipidic fragment. Every sub-library of tripeptides were labeled with graphite pencil. The vigorously stirred solution of DMT/NMM/TosO- (8) $(8.26 \mathrm{~g}, 20 \mathrm{mmol})$ in DCM (50 $\mathrm{ml})$ was cooled to $0-5{ }^{\circ} \mathrm{C}$, treated with carboxylic acid $(20 \mathrm{mmol})$ and NMM $(0.75 \mathrm{ml}, 6.7$ mmol). Stirring was continued at $0-50^{\circ} \mathrm{C}$ for $4 \mathrm{~h}$ and a set of every sub-library was immersed into suspension and gently shaken at room temperature for $24 \mathrm{~h}$. After this the plates were soaked and washed with DCM (4 x $100 \mathrm{ml})$, DMF (2 x 100ml) and DCM (2 x 100ml). 
The procedure was used for acylation of modified cellulose with (Z)-octadec-9-enoic acid (9) (5.64 g, $20 \mathrm{mmol}$ ) to obtain the $N$-lipidated peptides: 9.E,H,S; 9,E,S,H; 9,H,E,S; 9,H,S,E; 9.S,E,H and 9,S,H,E; immobilized on $\mathbf{1 7 .}$

Acylation with $(9 Z, 12 R)$-12-hydroxyoctadec-9-enoic acid (10) (5.97 g, $20 \mathrm{mmol}$ ) gave $N$ lipidated peptides: 10.E,H,S; 10,E,S,H; 10,H,E,S; 10,H,S,E; 10.S,E,H and 10,S,H,E; immobilized on 17.

Acylation with undec-10-enoic acid (11) (3.68 g, $20 \mathrm{mmol}$ ) gave $N$-lipidated peptides: 11.E,H,S; 11,E,S,H; 11,H,E,S; 11,H,S,E; 11.S,E,H and 11,S,H,E; immobilized on 17.

Acylation using the decanoic acid (12) (2.88 g, $20 \mathrm{mmol})$ gave $N$-lipidated peptides: 12.E,H,S; 12,E,S,H; 12,H,E,S; 12,H,S,E; 12.S,E,H and 12,S,H,E; immobilized on 17.

Acylation using the (Z)-docos-13-enoic acid (13) $(6.77 \mathrm{~g}, 20 \mathrm{mmol})$ gave $N$-lipidated peptides:

13.E,H,S; 13,E,S,H; 13,H,E,S; 13,H,S,E; 13.S,E,H and 13,S,H,E; immobilized on 17.

Acylation using the octadecanoic acid (14) (5.69 g, $20 \mathrm{mmol})$ gave $N$-lipidated peptides:

14.E,H,S; 14,E,S,H; 14,H,E,S; 14,H,S,E; 14.S,E,H and 14,S,H,E; immobilized on 17.

Removing of side chain protecting groups. Functionalized cellulose plates were treated with $100 \mathrm{ml}$ solution of TFA in DCM (50\% v/v) in the presence of triispropylsilane (TIS) (2\% v/v) and water $(3 \% \mathrm{v} / \mathrm{v})$ for $2 \mathrm{~h}$. Then, plates were washed with DCM $(2 \times 50 \mathrm{ml}), \mathrm{EtOH}(2 \times 50 \mathrm{ml})$, DCM $(2 \times 50 \mathrm{ml})$ and dried in the desiccator. All sheets were divided into small strips $(3 \times 16$ $\mathrm{mm})$. Each strip was individually labeled with graphite pencil and treated with phosphate buffer $\mathrm{pH} 7$ just before used in experiments.

Hydrolysis of Z-L-Leu-L-Leu-ONp (15) in the presence of artificial receptors. Equal-sized strips $(3 \times 16 \mathrm{~mm})$ of each member of the library were fastened round the side walls of ELISA plate wells is such a way as to avoid disturbing light transmission. A mixture water/methanol $(20 \% \mathrm{v} / \mathrm{v}, 150 \mu \mathrm{L})$ was added, and the extinction of the solution was measured at $405 \mathrm{~nm}$ with a $120 \mathrm{sec}$ time interval using a Sunrise-Tecan microplate reader. Collected data were processed with Excell and are collected in Tables 1-3 in Supplementary material and presented as graphs on Figures 1-5.

\section{Acknowledgements}

This study was supported by the Ministry of Science and High Education under the Research Project N N204 326737 and Research Project N N405 669540.

\section{Supporting Information Available}

Elemental analysis of selected members of library of N-acylated tripeptides immobilized on 17, preparative procedures used for synthesis of uncompleted structures of catalysts. 


\section{References}

1. (a) Fraczyk, J.; Kaminski, Z. J. J. Comb. Chem. 2008, 10, 934. (b) Fraczyk, J.; Malawska, B,; Kaminski, Z. J. J. Comb. Chem. 2009, 11, 446.

2. Fraczyk, J.; Kolesinska, B.; Czarnecka, A.; Malawska, B.; Wieckowska, A.; Bajda, M.; Kaminski, Z. J. QSAR \& Comb. Sci. 2009, 28, 728.

3. (a) Murakami, Y.; Kikuchi, J.; Hisaeda, Y.; Hayashida, O. Chem. Rev. 1996, 96, 721. (b) Waldrop, M. M. Science 1989, 245, 354. (c) Bjerre, J.; Roussea, C.; Marinescu, L.; Bols, M. Appl. Microbiol. Biotechn. 2008, 81, 1. (d) Xiao, J.; Xu, F-X.; Lu, Y-P.; Loh, T-P. Org. Lett. 2010, 12, 1220.

4. Kaminski, Z. J.; Kolesinska, B.; Kolesinska, J.; Sabatino, G.; Chelli, M.; Rovero, P.; Blaszczyk, M.; Głowka, M. L.; Papini, A. M. J. Am. Chem. Soc. 2005, 127, 16912.

5. Kolesinska, B.; Fraczyk, J.; Papini, A. M.; Kaminski, Z. J. Chemistry Today (Chimica Oggi) 2007, 25, 26.

6. Ryuichi, U.; Yoshito, M.; Tetsuo, I.; Yoko, M.; Yasu, K. Chem. Pharm. Bull. 1994, 42, 173.

7. Fraczyk, J.; Mrozek, A.; Kaminski, Z. J. Bioelectrochemistry 2010, 80: 2.

8. (a) Zhang, Y.; Lu, Z.; Desai, A.; Wulff, W. D. Org. Lett. 2008, 10, 5429. (b) Klein, G.; Humbert, N.; Gradinaru, J.; Ivanova, A.; Gilardoni, F.; Rusbandi, U. E.; Ward, T. R. Angew. Chem. Int. Ed. 2005, 44, 7764. (c) Xue, S.; Yu, S.; Deng, Y.; Wulff, W. D. Angew. Chem. Int. Ed. 2001, 40, 2271. (d) Motherwell, W. B.; Bingham, M. J.; Six, Y. Tetrahedron 2001, 57,4663 . 